\title{
Composite material characterization through biaxial testing of cruciform specimens
}

\author{
C. Ramault ${ }^{1, \mathrm{a}}$, A. Makris ${ }^{1}$, D. Van Hemelrijck ${ }^{1}$, E. Lamkanfi ${ }^{2}$ and W. Van Paepegem ${ }^{2}$ \\ ${ }^{1}$ Vrije Universiteit Brussel (VUB), Department of Mechanics of Materials and Constructions, \\ Pleinlaan 2, 1050 Brussels, Belgium \\ ${ }^{2}$ Ghent University, Department of Mechanical Construction and Production, Sint-Pietersnieuwstraat \\ 45, 9000 Ghent, Belgium
}

\section{Introduction}

Composite materials are applied in a variety of industrial sectors such as aeronautics, marine, construction and energy. The composite components are in general subjected to complex loadings, which lead to multiaxial stress states in the material. To accurately design these composite laminates, failure criteria which are not only verified with uniaxial but also with biaxial test data have to be used. Despite the large demand for this experimental information, there is little existing experimental capability to evaluate the biaxial response of composite materials [1].

One of the techniques to produce biaxial stress states in a composite laminate consists of applying in-plane biaxial loads to a cruciform specimen [2]. Such a test device and a suitable specimen geometry have been developed at the Vrije Universiteit Brussel [3]. As you can see in Figure 1, the specimen has an adapted fillet corner radius and a reduced thickness in the centre to ensure biaxial failure in the gauge section.

One of the objectives of biaxial testing is to obtain the failure stresses and strains in order to determine the failure envelopes of a certain material and lay-up. Another aim can be the determination of the mechanical material parameters in one single experimental set-up. It is clear that, due to the complex specimen geometry, the determination of these material characteristics is not straightforward and cannot be obtained as with uniaxial tests.

\section{Material characterization}

When performing a biaxial test, several material characteristics are of interest. The author will discuss the determination of the strain, stress and stiffness parameters in this paper.

\subsection{Strain}

The strain characteristics are obtained through full-field measurements like Digital Image Correlation [4]. Because of the specific geometry and corresponding heterogeneous strain field, the use of local strain measuring techniques such as strain gages is not adequate. The application of several strain measuring techniques is briefly discussed.

\footnotetext{
a e-mail : cramault@vub.ac.be
} 


\subsection{Strength}

In this paper, the emphasis will be on the determination of the strength characteristics. In a uniaxially loaded coupon specimen, the average stress is easy to determine by calculating dividing the applied force by the loaded area. When testing the complex cruciform geometry, the exact loaded area is unknown, and thus it is not straightforward to calculate the stress field.

Several approaches can be followed to estimate the stress field of the biaxially loaded specimen. Methods based on uniaxial strength data and a combination of measured strain data and the constitutive laws were already discussed in previous articles ([3], Figure 2). Other approaches are the calculation of a bypass factor [2] and the use of the measured displacement field together with a Finite Element (FE) model. These stress calculation methods are evaluated and their pro's and con's are discussed.
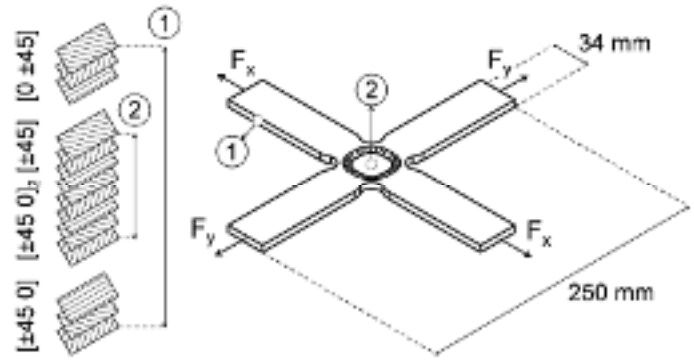

Fig. 1. Cruciform specimen geometry.

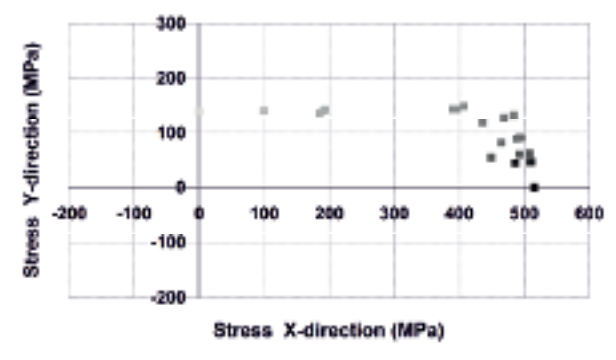

Fig. 2. First quadrant of an experimental failure envelope, determined by one of the approaches.

\subsection{Stiffness}

Stiffness characteristics can be obtained using an inverse method for the indirect identification of the four in-plane elastic orthotropic parameters of a biaxially loaded cruciform composite specimen. Strain fields obtained by a Digital Image Correlation Technique are used as experimental data. In parallel, a FE model leads to a numerical representation of the strain fields. The material parameters are obtained by updating the initial parameters in the FE model until the numerical strain fields match the experimental strain fields. The basic principles of this method are described in [5]. In this paper, the ongoing of this research is described.

\section{References}

1. M. Hinton, A.S. Kaddour, P.D. Soden, Failure criteria in fibre reinforced polymer composites: the world-wide failure exercise (Elsevier, 2004)

2. J.S. Welsh, J.S. Mayes, C.T. Key, R.N. McLaughlin, J. Comp. Mat. 38, 2165 (2004)

3. D. Van Hemelrijck, A. Makris, C. Ramault, E. Lamkanfi, W. Van Paepegem, Proc. of IMechE part L: J. of Mat.: Des. \& Appl. 222, 231 (2008)

4. C. Ramault, A. Makris, D. Van Hemelrijck, E. Lamkanfi, W. Van Paepegem, Proc. ECCM13 (Stockholm, 2008)

5. D. Lecompte, A. Smits, H. Sol, J. Vantomme, D. Van Hemelrijck, Int. J. Solids Struc. 44, 1628 (2007) 